\title{
Adhesion potential of relining materials to polyamide and PMMA-based denture base materials: effect of surface conditioning methods
}

\author{
Kümbüloğlu, Övül ; Yildirim, Bengisu ; Al-Haj Husain, Nadin ; Özcan, Mutlu
}

\begin{abstract}
This study evaluated the bond strength of relining materials to different denture base materials polyamide and polymethylmethacrylate denture base materials after various surface conditioning methods. Denture base resin specimens $(\mathrm{N}=128 ; \mathrm{n}=8$ per group $)(10 \times 10 \times 2.5 \mathrm{~mm} 3)$ were fabricated out of injection-moulded thermoplastic polyamide resin (POL) (Deflex) and heat-polymerized polymethylmethacrylate (PMMA, Dura Dent) (HC). The specimens were randomly divided into 4 main groups according to different surface conditioning methods: (a) No conditioning, control (C), (b) grinding with green stone $(\mathrm{G})$, (c) application of primer (V), (d) silica coating with Al2O3 particles coated with SiO2 (Rocatec) (R). Half of the specimens in each group received auto-polymerized hard relining resin (GC, GC Reline Hard) and the other half PMMA based relining resin (SC, Dura Dent). After thermocycling $(\times 5000)$, the bonded specimens were tested under tensile forces $(0.5 \mathrm{~mm} / \mathrm{min})$. Data (MPa) were analyzed using Mann-Whitney U and Kruskal-Wallis tests (alpha =0.05). Bond strength of relining resins were significantly higher to PMMA than to POL, regardless of the conditioning method $(\mathrm{p}<0.05)$. While $\mathrm{R}$ positively affected the bond strength results $(\mathrm{p}<0.05)(4.99 \pm 1.65-3.27 \pm 1.31)$, application $\mathrm{V}$ or $\mathrm{G}$ did not show significant effect to POL-relining resin adhesion. After $\mathrm{R}$ conditioning, bond strength values were significantly higher in HC-GC group $(7.48 \pm 2.32)$ than POL-GC group $(3.27 \pm 1.31)(\mathrm{p}<0.05)$. Adhesion of auto-polymerized relining materials to thermoplastic polyamide or polymethylmethacrylate denture resins could be improved after surface conditioning with silica-coating.
\end{abstract}

DOI: https://doi.org/10.1080/01694243.2019.1617935

Posted at the Zurich Open Repository and Archive, University of Zurich

ZORA URL: https://doi.org/10.5167/uzh-183145

Journal Article

Accepted Version

Originally published at:

Kümbüloğlu, Övül; Yildirim, Bengisu; Al-Haj Husain, Nadin; Özcan, Mutlu (2019). Adhesion potential of relining materials to polyamide and PMMA-based denture base materials: effect of surface conditioning methods. Journal of Adhesion Science and Technology, 33(17):1939-1947.

DOI: https://doi.org/10.1080/01694243.2019.1617935 
Adhesion potential of relining materials to polyamide and PMMA-based denture base materials: Effect of surface conditioning methods

\section{Övül Kümbüloğlu, DDS, PhDa / Bengisu Yildirim, DDS, PhDb/}

Nadin Al-Haj Husain, MDent, Dr. med. Dentc / Mutlu Özcan, DDS, Dr.med.dent., Ph.Dd

aProfessor, Ege University, Faculty of Dentistry, Department of Prosthodontics, Izmir, Turkey ${ }_{b}$ Assistant Professor, Usak University, Faculty of Dentistry, Department of Prosthodontics, Usak, Turkey cSpecialization Candidate, University of Bern, Department of Reconstructive Dentistry and Gerodontology, School of Dental Medicine, Bern, Switzerland ${ }_{b}$ Professor, University of Zurich, Dental Materials Unit, Center for Dental and Oral Medicine, Clinic for Fixed and Removable Prosthodontics and Dental Materials Science, Zurich, Switzerland

Short title: Adhesion of relining materials to polyamide and PMMA

Correspondance to: Prof. Dr. med. dent. Mutlu Özcan, University of Zürich, Dental Materials Unit, Center for Dental and Oral Medicine Clinic for Fixed and Removable Prosthodontics and Dental Materials Science, Plattenstrasse 11, CH-8032, Zürich, Switzerland. Tel: +41-44-63 45600, e-mail: mutluozcan@hotmail.com 
Abstract: This study evaluated the bond strength of relining materials to different denture base materials polyamide and polymethylmethacrylate denture base materials after various surface conditioning methods. Denture base resin specimens $(\mathrm{N}=128 ; \mathrm{n}=8$ per group) $(10 \times 10 \times 2.5 \mathrm{~mm} 3)$ were fabricated out of injectionmoulded thermoplastic polyamide resin (POL) (Deflex) and heat-polymerized polymethylmethacrylate (PMMA, Dura Dent) $(\mathrm{HC})$. The specimens were randomly divided into 4 main groups according to different surface conditioning methods: a) No conditioning, control (C), b) grinding with green stone $(G)$, c) application of primer (V), d) silica coating with $\mathrm{Al}_{2} \mathrm{O}_{3}$ particles coated with $\mathrm{SiO}_{2}$ (Rocatec) (R). Half of the specimens in each group received auto-polymerized hard relining resin (GC, GC Reline Hard), and the other half PMMA based relining resin (SC, Dura Dent). After thermocycling (x5000), the bonded specimens were tested under tensile forces $(0.5 \mathrm{~mm} / \mathrm{min})$. Data $(\mathrm{MPa})$ were analyzed using Mann Whitney $U$ and Kruskal Wallis tests (alpha $=0.05)$. Bond strength of relining resins were significantly higher to PMMA than to POL, regardless of the conditioning method $(p<0.05)$. While R positively affected the bond strength results $(p<0.05)(4.99 \pm 1.65-3.27 \pm 1.31)$, application $V$ or $\mathrm{G}$ did not show significant effect to POL-relining resin adhesion. After $\mathrm{R}$ conditioning, bond strength values were significantly higher in HC-GC group (7.48 \pm 2.32$)$ than POL-GC group $(3.27 \pm 1.31)(p<0.05)$. Adhesion of auto-polymerized relining materials to thermoplastic polyamide or polymethylmethacrylate denture resins could be improved after surface conditioning with silica-coating.

Keywords: Adhesion; Air-abrasion; Denture base material; Polyamide; Polymethylmethacrylate; Slica-coating; Surface conditioning; Relining resin 


\section{Introduction}

In partial removable dentures, the metal denture bases and clasps are typically made of metals and compromise aesthetic expectations in visible areas of the mouth. Such metallic denture bases or clasps are replaced with thermoplastic polyamide resin since 1950 [1-4].

The advantages of polyamide resins are higher elasticity and toxicological safety for patients with resin monomer and metal allergy [5-10]. In addition, polyamide is an injection-moulded thermoplastic resin that do not yield to polymerization shrinkage and formation of non-polymerized residual monomers when compared to chemical polymerization [11]. Also, flexible and almost translucent clasps provide denture retention by utilizing undercuts of abutment teeth [12]. However, polyamide resins are prone to high water sorption and thereby decreased compressive strength, bacterial contamination, discoloration, and bonding difficulties with autopolymerized resins [12-14]. Insufficient bond strength between polyamide or polymethylmethacrylate resins and relining resins [15], require initial surface conditioning of the denture resin in order to increase physicochemical interactions with the relining resin that could be applied either at the laboratory or chairside where the latter is easier and faster than laboratory procedures [16].

After polymerization of chairside auto-polymerized relining resins, higher amounts of residual monomer are usually present and that allow for chemical reaction with the relining resin materials [12] but few studies evaluated the adhesion of relining materials to polyamide denture base materials using auto-polymerized relining resins in the literature $[11,12,16]$.

The objective of this present study therefore, was to evaluate the bond strength between auto-polymerized relining resins and denture base resins after different surface conditioning methods. The null hypothesis tested was that surface conditioning methods would not show significant effect on the bond strength results. 


\section{Materials and Methods}

The materials used in this study are listed in Table 1.

\section{Specimen preparation}

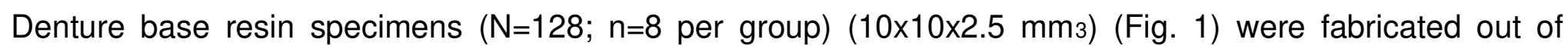
injection-moulded thermoplastic polyamide resin (POL) (Deflex, Nuxen SRL, Argentina) and heat-polymerized polymethylmethacrylate (PMMA) (Dura Dent, Izmir, Turkey) (HC).

The specimens were randomly divided into 4 main groups according to different surface conditioning methods:

\section{Surface conditioning methods}

No conditioning, control (C): In this group, denture resins were only polished with silicone carbide papers in the order of $(1000,1500,2000$ grit, for $20 \mathrm{~s}$ each, $1500 \mathrm{rpm}$ ) (SiC paper, Piramit, Istanbul, Turkey) and did not receive any conditioning.

Grinding with green stone $(\mathrm{G})$ : Denture resins were grinded with green stone (Stone Point Blaudent, Efes Dental, Bursa, Turkey) for $15 \mathrm{~s}$ at $500 \mathrm{rpm}$.

Application of primer (V): Denture resins were coated with one layer of primer using microbrush (V Primer, Sun Medical, Moriyama, Japan) and waited for its reaction for 5 minutes.

Silica coating $(R)$ : In this group, the specimens were air-abraded first with $110 \mu \mathrm{m} \mathrm{Al} \mathrm{O}_{3}$ particles (Rocatec Pre,

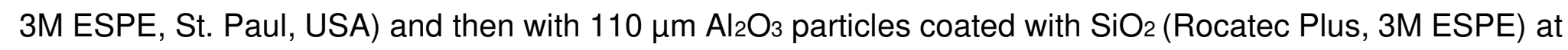
a pressure of 2.8 bars from a distance of $10 \mathrm{~mm}$ for $15 \mathrm{~s}$. Conditioned surfaces were silanated with a silane coupling agent (ESPE-Sil, 3M ESPE) and waited 5 minutes for its reaction.

The conditioned specimens in each group were embedded in silicone moulds with the adhesion surfaces exposed and randomly divided into two groups. While one half received auto-polymerized hard relining resin (GC) (GC Reline Hard, Tokyo, Japan), the other half received PMMA-based relining resin (SC) (Dura Dent). Relining materials were placed onto the conditioned specimens and the polymerized according to each 
manufacturer's recommendation. Table 2 presents the classification of specimens according to surface conditioning method.

The bonded specimens were then subjected to thermocycling ( $\left(x 5500,5-55^{\circ} \mathrm{C}\right.$, dwell time: $20 \mathrm{~s}$ ) (Esetron, Smart Robotechnologies, Ankara, Turkey).

\section{Tensile bond strength test}

The bonded specimens were mounted in the jig of the Universal Testing Machine (Shimadzu, Kyoto, Japan) (Fig. 2) and then subjected to the tensile bond strength (TBS) test at a crosshead speed of $0.5 \mathrm{~mm} / \mathrm{min}$. TBS values were recorded in MPa.

\section{Statistical analysis}

A sample size of 8 in each group was calculated to have more than $80 \%$ power to detect a difference with an effect size of $\mathrm{f}=0.364$ using a two-group Satterthwaite t-test (G*Power software version 3.1.10, Heinrich Heine University, Düsseldorf, Germany) with a 0.05 two-sided significance level. Statistical analysis was performed using SPSS 18.0 software (SPSS Windows, Chicago, IL, USA). Kolmogorov-Smirnov and Shapiro-Wilk tests were used to test normal distribution of the data. As the data were not homogeneously distributed, TBS data were analyzed using Mann-Whitney $U$ and Kruskall Wallis tests where the bond strength was the dependent variable and conditioning methods (7 levels: C, G, V, R), liner resin (2 levels: GC and SC) and denture resins (2 levels: POL and PMMA) as independent variables. $P$ values less than 0.05 were considered to be statistically significant in all tests.

\section{Results}

Bond strength of relining resins to denture resins were significantly affected by the denture resin type $(p<0.05)$, surface conditioning method $(p<0.05)$ but not with the liner resin material. Interaction terms were significant $(p<0.05)$. 
Regardless of the conditioning method, mean bond strengths of relining resins were significantly higher to PMMA than to $P O L(p<0.05)$.

While $R$ positively affected the bond strength results $(p<0.05)$, application $\vee$ or $G$ did not show significant effect to POL-relining resin adhesion (Table 2). After R conditioning, bond strength values were significantly higher in HC-GC group (7.48 \pm 2.32$)$ than POL-GC group $(3.27 \pm 1.31)(p<0.05)$.

There was no statistically significant difference between POL-SC (1.22 \pm 1.09$)$ and POL-GC $(2.16 \pm 1.16)$ $(p>0.05)$.

\section{Discussion}

This study evaluated the tensile bond strength between auto-polymerized relining resins and denture base resins after different surface conditioning methods. Since bond strength of relining resins to denture resins were significantly affected by the denture resin type, surface conditioning method, the null hypothesis tested could be rejected.

Polyamides are produced after a condensation reaction between the diamine $\mathrm{NH}_{2}-\left(\mathrm{CH}_{2}\right)_{6}-\mathrm{NH}_{2}$ and dibasic acid $\left.\mathrm{CO}_{2} \mathrm{H}-\left(\mathrm{CH}_{2}\right) 4-\mathrm{COOH}_{3}\right)[3,14]$. Polyamide is a crystalline polymer, and therefore highly chemical and heat resistant $[12,14]$. In the present study, as an accelerated aging test method, thermocycling was practiced for 5500 cycles between 5 and $55^{\circ} \mathrm{C}$. However, thermocycling does not represent the oral environment completely since saliva, $\mathrm{pH}$ changes and dynamic fatigue loading are not simulated [17]. Thermocycling typically causes a significant reduction in bond strength by weakening the resin structure [16]. When considering the water sorption of polyamides, it is reasonable explain the lower bond strength obtained in conjunction with POL.

In the present study, the bond strength between relining resins and denture base resins was measured using tensile test. This type of test method is commonly used to measure the bond strength between lining materials and denture resins but in order to obtain accurate results it is necessary to be sensitive to the force applied to the specimens $[2,12]$. 
Different surface treatments are required to increase the insufficient bond strength between polyamide resins and auto-polymerized relining resins $[9,16,18]$. In the present study, the most effective surface treatment was the tribochemical silica coating for group POL-GC. This may be due to mechanical interlocking and chemical bonding between the relining resin and polyamide denture base resin. In tribochemical silica coating, silicacoated aluminum oxides are deposited onto the surface and their kinetic energy transforms the thermal energy. The silica particles remaining on the surface after the coating forms a chemical bond with the silane coupling agent [11]. It has been previously reported that silica coating can improve the bond strength of polyamide resin to a chemically polymerized resin $[11,16,17]$. In the present study, first Rocatec Pre (particle size of $110 \mu \mathrm{m}$ ) and then Rocatec Plus (particle size of $110 \mu \mathrm{m}$ coated with silica) were blasted onto the polyamide surface. Air-abrasion could be performed using different particle size. The reason for choosing this particle size was due to favourable results reported with this particle size $[16,19]$. Katsumata et al [11] also suggested the use of smaller particle size (Rocatec soft) of $30 \mu \mathrm{m}$ alumina coated with silica for tribochemical silica coating of polyamide resins. Although it is claimed that polyamide surface Rocatec Plus removes more material from the surface, this was not noted in the present study.

After the application of Rocatec system followed by silane coupling agent treatment, Katsumata et al [11] reported bond strengths of $16.41 \mathrm{MPa}$ for specimens that were thermocycled and $13.18 \mathrm{MPa}$ for those not thermocycled. On the other hand, Hamanaka et al [16] reported less bond strength (5.8-6.6 MPa) for polyamides after tribochemical silica bonding with Rocatec. In another study, Hamanaka et al [16] stated TBS values of $(14.68 \pm 2.71 \mathrm{MPa})$ between Lucitone FRS polyamide resin and chairside auto-polymerized relining resin and (13.41 $\pm 1.74 \mathrm{MPa})$ between Valplast polyamide resin- chairside auto-polymerized relining resin after tribochemical silica coating with Rocatec. In the present study, after tribochemical silica coating with Rocatec, in groups POL-SC $(4.99 \pm 1.65 \mathrm{MPa})$ and POL-GC $(3.27 \pm 1.31 \mathrm{MPa})$ lower TBS values were found. The difference could be attributed to thermocycling of the specimens. After thermocycling, similar results were obtained by Hamanaka et al [16] for polyamide $(4.6 \pm 1.6 \mathrm{MPa})$ and PMMA $(5.7 \pm 0.5 \mathrm{MPa})$ after tribochemical 
silica coating. In the present study, without surface treatment for HC-SC group $(10.03 \pm 1.11 \mathrm{MPa})$ TBS value was found and after tribochemical silica coating $(11.4 \pm 451 \mathrm{MPa})$. The different test methods could be the

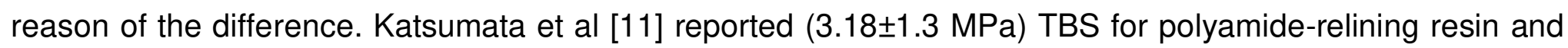
$(12.59 \pm 2.12 \mathrm{MPa})$ for heat polymerized denture resin-auto-polymerized relining resin. As a result, it is stated that Rocatec improves the adhesion results to polyamide resins. In this study, after surface conditioning with Rocatec, in POL-SC group (4.99 $\pm 1.65 \mathrm{MPa})$ TBS and in HC-SC group (11.4 $\pm 4.51 \mathrm{MPa})$ was noted found. The reason for the different results could be due to the selection of different brand of polyamides.

MMA is frequently preferable in dentures that also has better adhesion potential [20]. Further, organic solvents, such as chloroform, acetone, and methylene chloride (dichloromethane) have been used to enhance the adhesion [14,21-23]. In this regard, application of ethyl acetate was also proposed to prepare the surfaces of heat-polymerized denture base resins [19]. Also, when ethyl acetate and MMA were compared pretreatment with MMA increased the flexural strength of the polyamide denture base resin [18]. Nevertheless, chemically activated 4-META/MMA-TBB resin bonds to both of the chairside auto-polymerized relining resin and the silica layer $[16,20]$. Moreover, 4-META/MMA-TBB resin has smaller polymer particles which facilitates flowing on the surface $[16,24]$. The chemically polymerized and photo polymerized chairside relining resins are typically based on either PMMA or its copolymer polyethyl methacrylate (PEMA) [12]. Chairside auto-polymerized relining resin used in this study (GC Reline Hard) includes PMMA and silicon dioxide. Since this material is free of MMA in its composition, it does not cause chemical irritations to the oral tissues [20]. Also considering the low mean values and high standard deviations, the presence of MMA however was not sufficient to obtain acceptable results in conjunction with green stone or vinyl primer application, indicating that additional roughening was essential.

In this study, without surface conditioning in POL-SC and POL-GC groups presented significantly lower TBS which is in accordance with a previous study [12]. On the contrary, hard relining materials presented higher bond strength results to PMMA [2] which needs to be further investigated in conjunction with the surface 
conditioning methods applied in this study after thermocycling. Nevertheless, both polyamide and PMMA denture resins benefitted from tribochemical silica coating for better adhesion of relining resins tested in this study.

\section{Conclusions}

From this study, the following could be concluded:

1. Adhesion of relining resins to polyamide denture resin was inferior compared to polymethylmethacrylate.

2. Auto and heat-polymerized relining materials tested resulted in similar bond strength.

3. Compared to control group results, surface conditioning methods were to increase the adhesion of relining resin to polyamide and polymethylmethacrylate denture resins.

4. Tribochemical silica coating resulted in the highest bond strength between denture base materials and relining materials tested.

\section{Clinical Relevance}

In order to improve bond strength of auto-polymerized denture liners to denture base materials of polyamide resin or polymethylmethacrylate, denture resin base should be best conditioned using air-abrasion of $110 \mu \mathrm{m}$ $\mathrm{Al}_{2} \mathrm{O}_{3}$ particles coated with $\mathrm{SiO}_{2}$.

\section{Conflict of interest}

The authors did not have any commercial interest in any of the materials used in this study. 


\section{References}

[1] Goiato MC, Santos DM, Haddad MF, et al. Effect of accelerated aging on the microhardness and color stability of flexible resins for dentures. Braz. Oral Res. 2010;24:114-119.

[2] Yunus, N, Rashid AA, Azmi L, et al. Some flexural properties of a nylon denture base polymer. J. Oral Rehabil. 2005;32:65-71.

[3] Matthews E, Smith DC. Nylon as a denture base material. Br. Dent. J. 1955;98:231-237.

[4] Mutluay MM, Ruyter IE. Evaluation of adhesion of chairside hard relining materials to denture base polymers. J. Prosthet. Dent. 2005;94:445-452.

[5] Takabayashi Y. Characteristics of denture thermoplastic resins for non-metal clasp dentures. Dent. Mater. J. 2010;29:353-361.

[6] Takahashi Y, Chai J. Shear bond strength of denture reline polymers to denture base polymers. Int. J. Proshtodont. 2001;14:271-275.

[7] Takahashi Y, Hamanaka I, Shimizu H. Effect of thermal shock on mechanical properties of injection-molded thermoplastic denture base resins. Acta Odontol. Scand. 2012;70:297-302.

[8] Stafford GD, Huggett R, MacGregor AR, et al. The use of nylon as a denture-base material. J. Dent. $1986 ; 14: 18-22$.

[9] Kuwahara K. A case of using non-metal clasp partial denture for the patient with the metal allergy. Nihon Univ. J. Oral Sci. 2004;30:134-139.

[10] Shen C, Colaizzi FA, Birns B. Strength of denture repairs as influenced by surface treatment. J. Prosthet. Dent. 1984;52:844-848.

[11] Katsumata Y, Hojo S, Hamano N, et al. Bonding strength of autopolymerizing resin to nylon denture base polymer. Dent. Mater. J. 2009;28:409-418.

[12] Kim JH, Choe HC, Son MK. Evaluation of adhesion of reline resins to the thermoplastic denture base resin for non-metal clasp denture. Dent. Mater. J. 2014;33:32-38. 
[13] Vojdani M, Giti R. Polyamide as a denture base material: A literature review. J. Dent. 2015;16:1-9.

[14] Fueki K, Ohkubo C, Yatabe M, et al. Clinical application of removable partial dentures using thermoplastic resin. Part II: Material properties and clinical features of non-metal clasp dentures. J. Prosthodont. Res. 2014;58:71-84.

[15] Hamanaka I, Takahashi Y, Shimizu H. Mechanical properties of injection-molded thermoplastic denture base resins. Acta Odontol. Scand. 2011;69:75-79.

[16] Hamanaka I, Shimizu H, Takahashi Y. Shear bond strength of an autopolymerizing repair resin to injectionmolded thermoplastic denture base resins. Acta Odontol. Scand. 2013;71:1250-1254.

[17] Bulbul M, Kesim B. The effect of primers on shear bond strength of acrylic resins to different types of metals. J. Prosthet. Dent. 2010;103:303-308.

[18] Gundogdu M, Yanikoglu N, Bayindir F, et al. Effect of repair resin type and surface treatment on the repair strength of polyamide denture base resin. Dent. Mater. J. 2015;34:485-489.

[19]Hamanaka I, Shimizu H, Takahashi Y. Bond strength of a chairside autopolymerizing reline resin to injection-molded thermoplastic denture base resins. J. Prosthodont. Res. 2017;61:67-72.

[20] Vallittu PK, Lassila VP, Lappalainen R. Wetting the repair surface with methyl methacrylate affects the transverse strength of repaired heat-polymerized resin. J. Prosthet. Dent. 1994;72:639-643.

[21] Minami H, Suzuki S, Minesaki Y, et al. In vitro evaluation of the influence of repairing condition of denture base resin on the bonding of autopolymerizing resins. J. Prosthet. Dent. 2004;91:164-170.

[22] Sarac YS, Sarac D, Kulunk T, et al. The effect of chemical surface treatments of different denture base resins on the shear bond strength of denture repair. J. Prosthet. Dent. 2005;94:259-266.

[23] Shimizu H, Kakigi M, Fujii J, et al. Effect of surface preparation using ethyl acetate on the shear bond strength of repair resin to denture base resin. J. Prosthodont. 2008;17:451-455.

[24] Sarafianou A, Seimenis I, Papadopoulos T. Effectiveness of different adhesive primers on the bond strength between an indirect composite resin and a base metal alloy. J. Prosthet. Dent. 2008;99:377-387 


\section{Captions to figures and tables:}

\section{Tables:}

Table 1 Brands, abbreviations, chemical compositions and manufacturers of the materials used in this study. Table 2 Mean tensile bond strength values (MPa \pm Standard Deviations) of experimental groups. *Uppercase letters in one column represent statistically significant differences between groups and small letters within groups $(p<0.05)$. See Table 1 for group abbreviations.

\section{Figures:}

Fig. 1 Dimensions of the specimen with the relining resin material bonded to denture base resin.

Fig. 2 Schematic drawing of the specimen in the jig for the universal testing machine subjected to tensile bond strength test. 



\section{Tables:}

\begin{tabular}{|c|c|c|}
\hline Material & Chemical Composition & Manufacturer \\
\hline $\begin{array}{l}\text { Heat polymerized denture } \\
\text { base resin (PMMA) }\end{array}$ & PMMA, MMA & $\begin{array}{l}\text { Dura Dent, Erk Dental, } \\
\text { Izmir, Turkey }\end{array}$ \\
\hline $\begin{array}{l}\text { Polyamide denture base } \\
\text { resin (POL) }\end{array}$ & Polyamide & $\begin{array}{l}\text { Deflex, Nuxen S.R.L., } \\
\text { Buenos Aires, Argentina }\end{array}$ \\
\hline $\begin{array}{l}\text { Auto-polymerized relining } \\
\text { resin }(\mathrm{HC})\end{array}$ & PMMA, MMA, N,N-Bis (2-hydroxyethyl)para toluidine & Dura Dent \\
\hline $\begin{array}{l}\text { Auto-polymerized relining } \\
\text { resin }(\mathrm{GC})\end{array}$ & PMMA, Silicon dioxide & $\begin{array}{l}\text { GC Reline Hard, GC, } \\
\text { Tokyo, Japan }\end{array}$ \\
\hline Stone Bur (G) & Silicon carbide & $\begin{array}{l}\text { Stone point Blaudent, } \\
\text { Efes Dental, Bursa, Turkey }\end{array}$ \\
\hline Primer (V) & $\begin{array}{l}\text { 0.5\% 6-(4-vinylbenzyl-n-propyl)amino-l,3,5-triazine- } \\
\text { 2,4-dithiol (VBATDT), 99.5\% acetone }\end{array}$ & $\begin{array}{l}\text { V-primer, Sun Medical, } \\
\text { Moriyama, Japan }\end{array}$ \\
\hline Rocatec Pre (R) & $110 \mu \mathrm{m} \mathrm{Al}{ }_{2} \mathrm{O}_{3}$ particles & $\begin{array}{l}\text { 3M ESPE, } \\
\text { St. Paul, USA }\end{array}$ \\
\hline Rocatec Plus (R) & $110 \mu \mathrm{m} \mathrm{Al}{ }_{2} \mathrm{O}_{3}$ particles coated with $\mathrm{SiO}_{2}$ & 3M ESPE \\
\hline ESPE-Sil & 3-methacryloxyprophyltrimethoxy silane in ethanol & 3M ESPE \\
\hline
\end{tabular}

Table 1 Brands, abbreviations, chemical compositions and manufacturers of the materials used in this study. 


\begin{tabular}{|c|c|c|}
\hline $\begin{array}{l}\text { Surface Conditioning } \\
\text { ( } n=8 \text { per group) }\end{array}$ & Subgroups & Mean \pm Standard Deviation (MPa) \\
\hline \multirow[t]{4}{*}{$\mathbf{C}$} & HC-GC & $7.91 \pm 0.88 \mathrm{~A}, \mathrm{~b}$ \\
\hline & POL-SC & $2.61 \pm 2.68 \mathrm{~B}, \mathrm{~b}$ \\
\hline & POL-GC & $2.21 \pm 1.04 A, C$ \\
\hline & HC-SC & $10.03 \pm 1.11 \mathrm{~A}, \mathrm{a}$ \\
\hline \multirow[t]{4}{*}{$\mathbf{R}$} & HC-GC & $7.48 \pm 2.32 A, b$ \\
\hline & POL-SC & $4.99 \pm 1.65 \mathrm{~A}, \mathrm{C}$ \\
\hline & POL-GC & $3.27 \pm 1.31 \mathrm{~A}, \mathrm{c}$ \\
\hline & HC-SC & $11.4 \pm 4.51 \mathrm{~A}, \mathrm{a}$ \\
\hline \multirow[t]{4}{*}{$\mathbf{V}$} & HC-GC & $4.73 \pm 1.51 \mathrm{~B}, \mathrm{a}$ \\
\hline & POL-SC & $1.10 \pm 0.83 \mathrm{~B}, \mathrm{~b}$ \\
\hline & POL-GC & $2.54 \pm 1.66 \mathrm{~A}, \mathrm{~b}$ \\
\hline & HC-SC & $5.97 \pm 0.68 \mathrm{~B}, \mathrm{a}$ \\
\hline \multirow[t]{4}{*}{$\mathbf{G}$} & HC-GC & $4.34 \pm 1.44 \mathrm{~B}, \mathrm{~b}$ \\
\hline & POL-SC & $1.22 \pm 1.09 \mathrm{~B}, \mathrm{~d}$ \\
\hline & POL-GC & $2.16 \pm 1.17 \mathrm{~A}, \mathrm{C}$ \\
\hline & HC-SC & $8.56 \pm 2.77 \mathrm{AB}, \mathrm{a}$ \\
\hline
\end{tabular}

Table 2 Mean tensile bond strength values (MPa \pm Standard Deviations) of experimental groups. *Uppercase letters in one column represent statistically significant differences between groups and small letters within groups $(p<0.05)$. See Table 1 for group abbreviations. 
Figures:

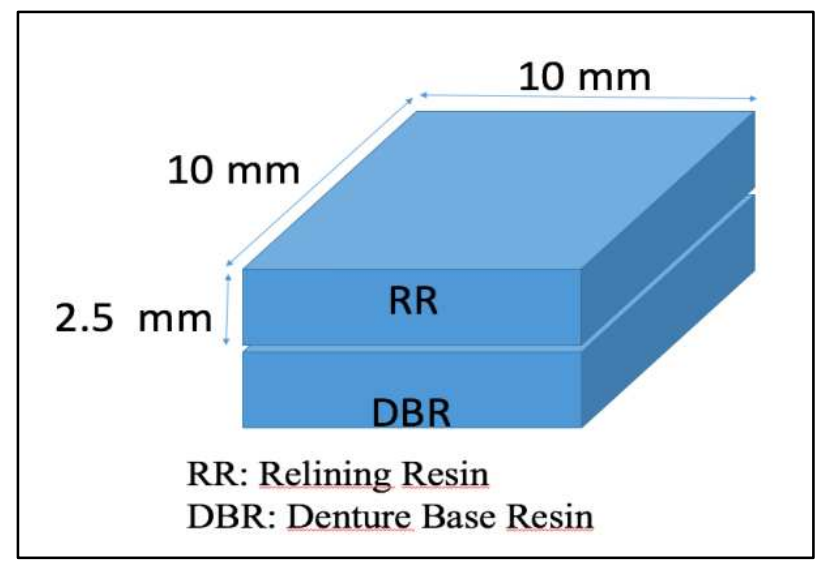

Fig. 1 Dimensions of the specimen with the relining resin material bonded to denture base resin.

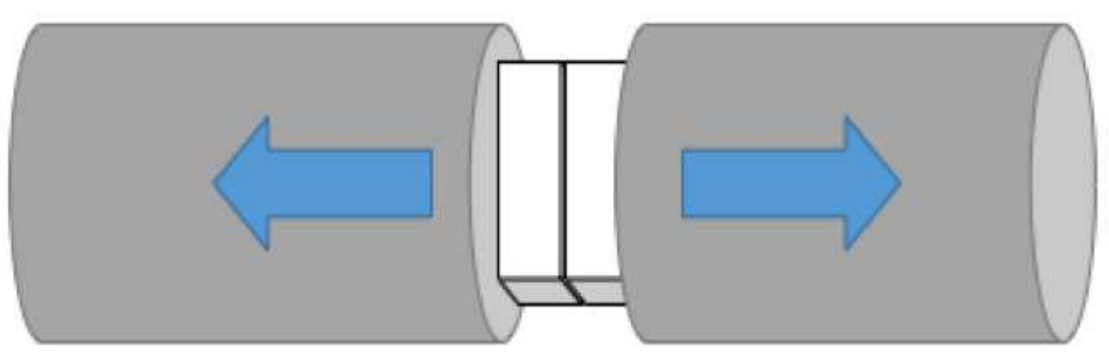

Fig. 2 Schematic drawing of the specimen in the jig for the universal testing machine subjected to tensile bond strength test. 